\title{
Old Myocardial Infarction by ECG Finding
}

National Cancer Institute

\section{Source}

National Cancer Institute. Old Myocardial Infarction by ECG Finding. NCI Thesaurus. Code C101597.

An electrocardiographic finding of pathologic Q waves, which is suggestive of myocardial infarction of one or more regions of the heart, without evidence of current or ongoing acute infarction. No specification is provided for localization. (CDISC) 